This synopsis is based on a report entitled 'Microclimate management and manipulation by traditional farmers in Tanzania. Final contest report'. Section Agricultura' Physics, Physics Department, University of Dar es Salaam (Tanzania), 1985. 23 pp., 42 refs. English.

Available as paper copy (order R036P, free of charge for those working in a developing country, $f 20$ including postage for others) or microfiche (order R036M, f 12.50 including postage) at: NARD, clo Pudoc, P.O. Box 4, 6700 AA Wageningen, Netherlands (telex 45015 blhwg nl).

\title{
Effect of pen size on the development of agonistic behaviour ${ }^{1}$ in piglets
}

G. J. Lammers and W. G. P. Schouten (Department of Animal Husbandry, Agricultural University, Marijkeweg 40, 6709 PG Wageningen, Netherlands)

Received 29 January 1985; accepted 4 April 1985

Abstract. The development of agonistic behaviour was studied during the first 8 weeks of life of piglets housed in pens of $28 \mathrm{~m}^{2}, 6.7 \mathrm{~m}^{2}$ and $3.5 \mathrm{~m}^{2}$. Litter size was $7-9$ piglets. The research was done by frequential and sequential analysis of behavioural interactions between piglets.

Key-words: agonistic behaviour, development, pig, piglet, pen size, sequential analysis.

Introduction. The development of intensive pig husbandry during the past 10-20 years has greatly altered the circumstances under which piglets are reared. While it is evident that floor area per piglet has been much reduced, there is reason to assume that the size of these modern pens has become too small for the development of normal agonistic behaviour. A preliminary study showed that the development of agonistic behaviour of piglets reared in a small pen was quite different from piglets grown up in a large pen (D. J. Dijk, personal communication). In the present study we compared the development of agonistic behaviour of piglets housed in 3 different pen sizes.

Material and methods. Videorecordings were made of behavioural interactions between piglets within 4 litters during the first 8 weeks of life. Two litters were housed

${ }^{1}$ Agonistic behaviour is all the behaviour between aggression and flight. 

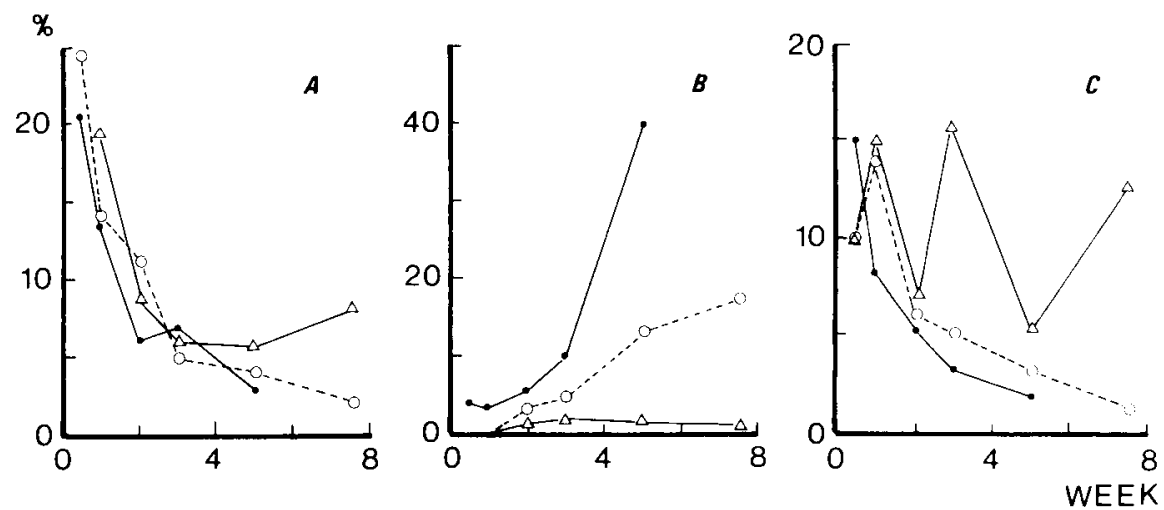

Fig. 1. Changes in the mean duration (as a percentage of total duration of a physical interactions) of nose contacts (A) and standing-in-front behaviour (B) over the first 8 weeks of life. The percentage of head knocks placed on the hindquarters is also shown (C) $-1-28 \mathrm{~m}^{2}, O-O=6.7 \mathrm{~m}^{2}, \Delta-\Delta$, $3.5 \mathrm{~m}^{2}$ ).

with tethered sows in pens of $3.5 \mathrm{~m}^{2}, 1$ litter was housed with a tethered sow in a pen of $6.7 \mathrm{~m}^{2}$ and 1 litter with a free sow in a pen of $28 \mathrm{~m}^{2}$. All pens had straw bedding. A behavioural interaction was defined as beginning 2 seconds before the first and ending 2 seconds after the last physical contact between two piglets. The last physical contact was a contact not followed within 10 seconds by a new one between the same piglets. From 9 or 10 pairs of piglets per pen size, the behaviour (frequencies (Siegel, 1956) and sequences (Haberman, 1973)) during behavioural interactions was analysed per second.

Results and discussion. While pen size did not influence the development of individual recognition (by nosing; Fig. 1A) there was a significant influence on the development of fighting behaviour. Piglets housed in pens of $3.5 \mathrm{~m}^{2}$ did not develop threatening behaviour (standing in front, Fig. 1B) and did not learn to place head knocks exclusively on the head and shoulders of other piglets (Fig. 1C). The typical sequences of agonistic behaviour also differed between housing conditions. In the pen of $6.7 \mathrm{~m}^{2}$, more than $40 \%$ of the behavioural interactions with head knocks after week 4 were preceded by threatening behaviour. In the pens of $3.5 \mathrm{~m}^{2}$ this was only $6 \%$. In this pen size, head knocks were mostly preceded by standing and approach behaviours, which in the pen of $6.7 \mathrm{~m}^{2}$ often preceded threatening behaviour. Because of the lack of threatening, the behaviour of piglets in the $3.5 \mathrm{~m}^{2}$ pens was unpredictable. It was possible, therefore, that a social hierarchy did not develop in these 2 litters. In the pens of $6.7 \mathrm{~m}^{2}$ and $28 \mathrm{~m}^{2}$, a social hierarchy was readily established. This was concluded from observations which indicated that, in the course of time, the frequencies of head knocks and walk-away behaviour became unequally distributed over the two piglets of each pair; one of the piglets clearly dominated.

It seemed that the development of agonistic behaviour of piglets grown up in 
pens of $3.5 \mathrm{~m}^{2}$ did not progress after week 2, thus older piglets showed infantile fighting. Furthermore, at an age of about 10 weeks -2 weeks after all the pigs had been transferred to straw pens of $8.7 \mathrm{~m}^{2}$ - they still showed abnormal agonistic behaviour in experimental encounters with unknown pigs (Lammers \& Schouten, 1985). From this we conclude that for the development of normal agonistic behaviour in group-housed pigs it is very important that the pens in which piglets are reared are large enough, presumably larger than $3.5 \mathrm{~m}^{2}$. Of course, the pens in which adult pigs are housed must also have a minimum size in order to allow the performance of normal agonistic interaction. On this latter aspect only preliminary data exist (Petherick, 1983).

\section{References}

Haberman, S. J., 1973. The analysis of residuals in cross-classified tables. Biometrics 29: 205-220.

Lammers, G. J. \& W. G. P. Schouten, 1985. Effects of pen size during rearing on later agonistic behaviour in piglets. Netherlands Journal of Agricultural Science 33: 297-299.

Petherick, J. C., 1983. A biological basis for the design of space in livestock housing. In: S. H. Baxter, M. R. Baxter \& J. A. C. MacCormick (Eds.), Farm Animals housing and welfare, p. 103-121. Martinus Nijhoff, The Hague.

Siegel, S., 1956. Nonparametric statistics for the behavioral sciences. MrGraw-Hill, Kogakusha Ltd, Tokyo, 312 pp.

This synopsis is based on a report entitled 'De invloed van kraamhokgrootte op de ontwikkeling van het agonistische gedrag bij varkens', Department of Animal Husbandry, Agricultural University, Wageningen, 1984. 43 pp., 17 figs., 11 tables, 27 refs., 1 appendix. Dutch, English summary and table and figure captions.

Available as paper copy (order R037P, $f 20$ including postage) or microfiche (order R037M, $f 12.50$ including postage) at: NARD, clo Pudoc, P.O. Box 4, $6700 \mathrm{AA}$ Wageningen, Netherlands (telex 45015 blhwg $\mathrm{nl}$ ).

\section{Effects of pen size during rearing on later agonistic behaviour $^{1}$ in piglets}

G. J. Lammers and W. G. P. Schouten (Department of Animal Husbandry, Agricultural University, Marijkeweg 40,6709 PG Wageningen, Netherlands)

Received 4 April 1985; accepted 12 June 1985

Abstract The agonistic behaviour during experimental social encounters between 2 unfamiliar pigs was studied in pigs ca. 10 weeks old reared in pens of $3.5 \mathrm{~m}^{2}$ or 6.7

1 Agonistic behaviour is all the behaviour between agression and flight. 